\title{
Dominance of multidrug resistant CC271 clones in macrolide-resistant Streptococcus pneumoniae in Arizona
}

\author{
Jolene R Bowers ${ }^{* *}$, Elizabeth M Driebe ${ }^{1}$, Jennifer L Nibecker ${ }^{1}$, Bette R Wojack ${ }^{2}$, Derek S Sarovich ${ }^{3}$, Ada H Wong $^{4}$, \\ Pius M Brzoska ${ }^{4}$, Nathaniel Hubert ${ }^{1}$, Andrew Knadler ${ }^{1}$, Lindsey M Watson ${ }^{3}$, David M Wagner ${ }^{3}$, Manohar R Furtado $^{4}$, \\ Michael Saubolle ${ }^{2,5}$, David M Engelthaler ${ }^{1}$ and Paul S Keim ${ }^{1,3}$
}

\begin{abstract}
Background: Rates of resistance to macrolide antibiotics in Streptococcus pneumoniae are rising around the world due to the spread of mobile genetic elements harboring mef(E) and erm(B) genes and post-vaccine clonal expansion of strains that carry them.

Results: Characterization of 592 clinical isolates collected in Arizona over a 10 year period shows 23.6\% are macrolide resistant. The largest portion of the macrolide-resistant population, $52 \%$, is dual mef(E)/erm(B)-positive. All dual-positive isolates are multidrug-resistant clonal lineages of Taiwan ${ }^{19 F}-14$, mostly multilocus sequence type 320, carrying the recently described transposon Tn2010. The remainder of the macrolide resistant S. pneumoniae collection includes 31\% mef(E)-positive, and 9\% erm(B)-positive strains.

Conclusions: The dual-positive, multidrug-resistant S. pneumoniae clones have likely expanded by switching to non-vaccine serotypes after the heptavalent pneumococcal conjugate vaccine release, and their success limits therapy options. This upsurge could have a considerable clinical impact in Arizona.
\end{abstract}

\section{Background}

Streptococcus pneumoniae is a major etiological agent of pneumonia, otitis media, sinusitis, and other respiratory pathology. Macrolides remain a primary antibiotic choice for physicians treating such infections due to their broad spectrum of activity, patient tolerance, easy outpatient treatment, high achievable tissue concentrations, and anti-inflammatory properties. Use of macrolides has led to increased rates of resistance in $S$. pneumoniae [1,2] and even clinical treatment failure in several cases [3-5]. Macrolide resistance rates in clinical isolates of $S$. pneumoniae vary greatly among countries [6-9].

The main mechanisms of macrolide resistance in $S$. pneumoniae also vary geographically. The erm(B) encoded methylation of the ribosomal macrolide target site, which confers high-level macrolide resistance as

\footnotetext{
* Correspondence: jbowers@tgen.org

${ }^{1}$ Translational Genomics Research Institute, Flagstaff, AZ, USA

Full list of author information is available at the end of the article
}

well as resistance to lincosamides and streptogramin $\mathrm{B}$ (MLS ${ }_{B}$ phenotype), is the prevalent mechanism in some Asian, European, Middle Eastern, and African countries [6,9-13]. The mef encoded efflux pump conferring lowlevel macrolide resistance ( $M$ phenotype) is more prevalent in other Asian and European countries and North America [9,14-16].

S. pneumoniae clones carrying both genes (dual-positive) have emerged as important clinical populations. These strains have serotypes not covered by the heptavalent pneumococcal conjugate vaccine (PCV7) released in 2000 and are multidrug resistant, posing a significant health threat. $[9,10,15,17,18]$. These dual-positive $S$. pneumoniae strains now comprise a substantial portion of macrolide resistant isolates in regions across the globe $[6,7,9,11,19]$.

A primary vehicle for lateral transfer of both genes is Tn2010, a transposon of the tetracycline resistance gene tet(M)-carrying Tn916 family with an inserted $\operatorname{erm}(\mathrm{B})$ element and mef(E)-containing mega element [20]. A second transposon carrying both $\operatorname{erm}(\mathrm{B})$ and $m e f(\mathrm{E})$,
C Biomed Central

(c) 2012 Bowers et al; BioMed Central Ltd. This is an Open Access article distributed under the terms of the Creative Commons Attribution License (http://creativecommons.org/licenses/by/2.0), which permits unrestricted use, distribution, and reproduction in any medium, provided the original work is properly cited. 
Tn2017, comprised of Tn916 with the erm(B)-carrying Tn917 and the mega element inserted, was found in a Hungarian isolate from 2003 [21]. Tn916-family transposons with various insertions are the basis of most erm (B)-carrying mobile genetic elements, while mef(E) is known to be only in variants of the mega element [20].

In this study, we characterize a set of macrolide resistant S. pneumoniae clinical isolates collected in Arizona based on $m e f(\mathrm{E})$ and $\operatorname{erm}(\mathrm{B})$ gene presence, multilocus sequence typing (MLST) and serotyping, antibiotic susceptibility profiles, and potential transposon carriage. We document likely episodes of capsule switching and serotype replacement, both mechanisms that allow $S$. pneumoniae to evade the PCV7 and cause infection in an immunized population.

\section{Methods \\ Bacterial isolates}

From 1999 to 2008, 592 S. pneumoniae isolates were collected by a large hospital reference laboratory that receives specimens from ten system-wide medical centers and a high volume private reference laboratory that receives specimens from regional inpatient, long-term care, and outpatient facilities. Isolates considered noninvasive were obtained from upper respiratory tract (upper respiratory specimens plus sinus, nasal, and nasopharyngeal swabs), lower respiratory tract, ear, eye, body fluid, wound, and tissue $(n=488)$. Isolates considered invasive were obtained from blood $(n=100)$, urine $(\mathrm{n}=2)$, and cerebrospinal fluid (CSF, $\mathrm{n}=2$ ) specimens. All were identified by bile solubility and optochin susceptibility testing. Patients ranged in age from 1 month to 88 years with a median age of 19 years and mean age of 29 1/2years.

\section{Antimicrobial susceptibility testing}

In vitro susceptibility testing followed Clinical and Laboratory Standards Institute (CLSI) recommended methodologies and interpretational zone of inhibition diameter and minimal inhibitory concentration (MIC) breakpoints [22]. Susceptibilities were determined for most isolates for penicillin, erythromycin, clindamycin, tetracycline, and trimethoprim-sulfamethoxazole by disk agar-diffusion (Kirby-Bauer), manual microdilution (MicroScan, Siemens Healthcare Diagnostics, Inc., Deerfield, IL), or gradient strip agar diffusion (E-test, AB Biodisk, Stockholm, Sweden) testing.

\section{DNA extraction}

Bacterial DNA was extracted for PCR using DNeasy Blood and Tissue Kit (Qiagen, Valencia, CA) following manufacturer's instructions for Gram-positive bacteria with the addition of $200 \mathrm{U}$ of mutanolysin (SigmaAldrich, St. Louis, MO).

\section{Real-time PCR}

Isolates were screened with commercial real-time PCR assays to detect $m e f(\mathrm{E}), \operatorname{mef}(\mathrm{A}), \operatorname{erm}(\mathrm{B})$, and tet(M) (Life Technologies, Foster City, CA). Real-time PCR was carried out in $10 \mu \mathrm{L}$ reactions containing $5 \mu \mathrm{L} 2 \mathrm{X}$ Taqman Universal PCR Mastermix (Life Technologies, Foster City, CA), $0.5 \mu \mathrm{L} 20 \mathrm{X}$ assay mix, and $0.2 \mathrm{ng}$ genomic DNA template. Screening was done on the $7900 \mathrm{HT}$ (Life Technologies, Foster City, CA) using the following thermal cycling conditions: $50^{\circ} \mathrm{C}$ for $2 \mathrm{~min}, 95^{\circ} \mathrm{C}$ for 10 min, and 40 cycles of $95^{\circ} \mathrm{C}$ for $15 \mathrm{~s}, 60^{\circ} \mathrm{C}$ for $1 \mathrm{~min}$.

\section{Multilocus sequence typing and serotyping}

Multilocus sequence typing (MLST) was performed using primer pairs described in the MLST database http://spneumoniae.mlst.net/[23]. Allele profiles and sequence types were also obtained from the database. Strains differing by one of the seven MLST loci were designated single-locus variants (SLVs).

PCR deduction of serotypes was performed on select isolates as described at http://www.cdc.gov/ncidod/biotech/strep/pcr.htm[24-27], with the addition of a previously described PCR to differentiate serotype 6A from 6B [28].

\section{Transposon detection PCR}

Primers previously described, some with slight modifications to adjust melting temperatures, were used to detect regions of transposons known to carry antibiotic resistance genes (Table 1). In brief, selected isolates were subject to PCR using primers for the genes int and $x i s$, and $\operatorname{tnpR}$ and $\operatorname{tnp} A$ to detect the presence of transposons in the Tn916 and Tn917 families respectively [29]. Depending on their resistance gene profile, some isolates positive for only Tn916 were subject to PCR using the following primer pairs: SG1 and LTf [30] to substantiate the presence of $\operatorname{Tn} 2009$ or $\operatorname{Tn} 2010$ with a 1 kb PCR product, EB2 [31] and TN2 [32] to confirm Tn2010 with a $3.3 \mathrm{~kb}$ PCR product, and J12 and J11 to detect and differentiate Tn6002 (3.6 kb PCR product) from $\operatorname{Tn} 6003 / \operatorname{Tn} 1545$ (7.9 kb PCR product) [33]. Isolates positive for both transposon families were subject to PCR using primers J12 and J11 to detect Tn3872 with an 800 bp PCR product. Amplicon presence or absence and sizes analyzed via gel electrophoresis guided the identification of transposon presence and type; authors concede these are presumptions based on published transposon maps and therefore limited data.

\section{Results}

\section{Macrolide resistance}

In our collection of 592 S. pneumoniae isolates, 140 (23.6\%) are erythromycin resistant, including only 5 of the 104 invasive isolates. Within the erythromycin 
Table 1 Oligonucleotides used in transposon detection

\begin{tabular}{|c|c|c|c|c|c|c|}
\hline $\begin{array}{l}\text { Transposon } \\
\text { region }\end{array}$ & $\begin{array}{l}\text { Oligo } \\
\text { nucleotide }\end{array}$ & Sequence & $\begin{array}{l}\text { Amplicon } \\
\text { size (bp) }\end{array}$ & $\begin{array}{l}\text { Transposon } \\
\text { presumed } \\
\text { present }\end{array}$ & $\begin{array}{l}\text { S. pneumoniae } \\
\text { population screened }\end{array}$ & Reference \\
\hline \multirow[t]{2}{*}{ int gene } & int_for & GCGTGATTGTATCTCACT & 1046 & Tn916 & $\begin{array}{l}\text { Dual-positive, erm(B)- } \\
\text { positive, mef(E)-positive }\end{array}$ & [29] \\
\hline & int_rev & GACGCTCCTGTTGCTTCT & & & & {$[29]$} \\
\hline \multirow[t]{2}{*}{ xis gene } & xis_for & AAGCAGACTGAGATTCCTA & 193 & Tn916 & $\begin{array}{l}\text { Dual-positive, erm(B)- } \\
\text { positive, mef(E)-positive }\end{array}$ & [29] \\
\hline & xis rev & GCGTCCAATGTATCTATAA & & & & [29] \\
\hline \multirow[t]{2}{*}{ tnpRgene } & $\mathrm{O} 21$ & CCAAGGAGCTAAAGAGGTCCC & 1528 & Tn917 & $\begin{array}{l}\text { Dual-positive, erm(B)- } \\
\text { positive, mef(E)-positive }\end{array}$ & [29] \\
\hline & $\mathrm{O} 22$ & GTCCCGAGTCCCATGGAAGC & & & & [29] \\
\hline \multirow[t]{2}{*}{ tnpA gene } & $\mathrm{O} 23$ & GCTTCCATGGGACTCGGGAC & 2115 & Tn917 & $\begin{array}{l}\text { Dual-positive, erm(B)- } \\
\text { positive, mef(E)-positive }\end{array}$ & [29] \\
\hline & $\mathrm{O} 24$ & GCTCCCAATTAATAGGAGA & & & & [29] \\
\hline \multirow{3}{*}{$\begin{array}{l}\text { Spans insert of erm } \\
\text { (B) elements in } \\
\text { Tn916 } \\
\end{array}$} & $J 12^{d}$ & ATTCCCATTGAAGACGCAGAAGT & 800 & $\operatorname{Tn} 3872$ & $\begin{array}{l}\text { erm(B)-positive that are } \\
\text { Tn916-positive }\end{array}$ & [34] \\
\hline & $\mathrm{J} 11^{\mathrm{d}}$ & CTACCGCACTTCGTITGGTGTAC & 3600 & Tn6002 & & [34] \\
\hline & & & 7900 & $\begin{array}{l}\text { Tn6003 or } \\
\text { Tn1545 }\end{array}$ & & \\
\hline \multirow[t]{2}{*}{$\begin{array}{l}\text { Junction of mega } \\
\text { insert and Tn916 }\end{array}$} & SG1 & CTCACTGCACCAGAGGTGTA & 1000 & $\begin{array}{l}\text { Tn2009 or } \\
\text { Tn2010 }\end{array}$ & $\begin{array}{l}\text { Dual-positive and mef(E)- } \\
\text { positivie that are Tn916- } \\
\text { positive }\end{array}$ & {$[30]$} \\
\hline & LTf & GCAGAGTATACCATTCACATCGAAGTTCCAC & & & & 30] \\
\hline \multirow[t]{2}{*}{$\begin{array}{l}\text { Junction of erm(B) } \\
\text { element and } \operatorname{Tn} 916\end{array}$} & EB2 & AGTAATGGTACTTAAATTGTTTAC & 3300 & $\operatorname{Tn} 2010$ & $\begin{array}{l}\text { Dual-positive that are } \\
\text { Tn916-positive }\end{array}$ & {$[31]$} \\
\hline & $\mathrm{TN}^{\mathrm{a}}$ & GAAGTA(G/C)AAGCTAAAGATGG & & & & [32] \\
\hline
\end{tabular}

${ }^{a}$ Modified from original to change melt temperature or incorporate degeneracies

resistant population, at least $110(78.6 \%)$ are multidrug resistant, defined here as resistant to antibiotics in at least 3 different classes or 2 classes and positive for the tet $(\mathrm{M})$ gene if not tested for tetracycline susceptibility.

Of the 140 erythromycin resistant strains, 44 (31.4\%) were $m e f(\mathrm{E})$-positive including three invasive isolates, 13 (9.3\%) were $\operatorname{erm}(\mathrm{B})$-positive including one invasive isolate, and $73(52.1 \%)$ were dual mef(E)/erm(B)-positive including one invasive isolate. One isolate was positive for mef(A). Nine (6.4\%) were negative for the macrolide resistance genes and no further analyses were conducted to determine their resistance mechanisms. Thirty-eight of the mef(E)-positive isolates expressed the M-phenotype while six expressed the $\mathrm{MLS}_{\mathrm{B}}$ phenotype, manifesting alternative clindamycin resistance mechanisms. All $13 \mathrm{erm}(\mathrm{B})$-positive isolates showed $\mathrm{MLS}_{\mathrm{B}}$. Sixty-eight of the dual-positive isolates showed $\mathrm{MLS}_{\mathrm{B}}$; the remaining five expressed the M-phenotype suggesting clindamycin resistance is inducible or erm(B) is non-functional in these isolates.

Ten of the 452 erythromycin susceptible isolates were $m e f(\mathrm{E})$-positive, one was $\operatorname{erm}(\mathrm{B})$-positive, and five were dual-positive, signifying a loss of gene function in these isolates.

\section{Time series}

Macrolide resistance rates in our collection increased from 1999 to 2004, then stabilized through 2008 (Table 2).

Dual-positive numbers grew steadily over the 10-year duration of the study from $39.1 \%$ to $67.5 \%$ of all macrolide resistant isolates. Concurrently, the proportion mef (E)-positive fell $(47.8 \%$ to $25.0 \%)$ and the proportion of $\operatorname{erm}$ (B)-positive remained relatively steady until 20072008 (Table 2).

According to MLST and serotype deduction, strain dominance and diversity changed for all three populations over the 10 years (Table 2, Figure 1). The most prevalent sequence types of the early dual-positive population include ST271 and various single locus variants (SLVs) that all belong to clonal complex (CC) 271. Through 2004, all isolates $(\mathrm{n}=15)$ in this population except the two ST320 isolates serotyped as 19F, a vaccine type (VT). ST320, a SLV of ST271, became dominant in our collection more recently, and almost exclusively by 2008 . Of the 39 ST320 isolates serotyped, all were found to be a non-vaccine type (NVT) serotype 19A. This is consistent with the well-documented serotype switch in S. pneumoniae isolates in the U.S. $[35,36]$. 
Table 2 Time series of macrolide resistance gene presence, sequence types, and serotypes in S. pneumoniae clinical isolates

\begin{tabular}{|c|c|c|c|c|c|c|c|c|c|}
\hline \multirow[b]{3}{*}{$\begin{array}{l}\text { Macrolide-resistant } S \text {. } \\
\text { pneumoniae } \\
\text { population }\end{array}$} & \multirow{2}{*}{\multicolumn{2}{|c|}{$1999-2000$}} & \multicolumn{7}{|c|}{ Time period } \\
\hline & & & \multirow{2}{*}{ 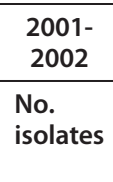 } & \multicolumn{2}{|c|}{$2003-2004$} & \multicolumn{2}{|c|}{$2005-2006$} & \multicolumn{2}{|c|}{$2007-2008$} \\
\hline & $\begin{array}{l}\text { Sequence } \\
\text { types (no. } \\
\text { isolates) }\end{array}$ & $\begin{array}{l}\text { Serotyp } \\
\mathrm{e}^{\mathrm{a}} \text { (no. } \\
\text { tested) }\end{array}$ & & $\begin{array}{l}\text { Sequence } \\
\text { types (no. } \\
\text { isolates) }\end{array}$ & $\begin{array}{l}\text { Serotype } \\
\text { (no. } \\
\text { tested) }\end{array}$ & $\begin{array}{l}\text { Sequence } \\
\text { types (no. } \\
\text { isolates) }\end{array}$ & $\begin{array}{l}\text { Serotype }^{a} \\
\text { (no. } \\
\text { tested) }\end{array}$ & $\begin{array}{l}\text { Sequence } \\
\text { types (no. } \\
\text { isolates) }\end{array}$ & $\begin{array}{l}\text { Serotype } \\
\text { (no. } \\
\text { tested) }\end{array}$ \\
\hline \multirow{8}{*}{$\begin{array}{l}\text { Dual mef(E)/erm(B)- } \\
\text { positive }\end{array}$} & $271(4)$ & 19F (4) & 0 & $320^{\mathrm{b}}(2)$ & 19A (2) & $320^{\mathrm{b}}(19)$ & 19A (16) & $320^{\mathrm{b}}(24)$ & 19A (21) \\
\hline & $\overline{1412^{\mathrm{b}, \mathrm{e}}(1)}$ & $19 F(1)$ & & $1396^{\mathrm{b}}(2)$ & $19 F(2)$ & $320^{\mathrm{b}, \mathrm{e}}(2)$ & 19A (1) & $1459^{b}(1)$ & NT \\
\hline & $3039^{\mathrm{b}, \mathrm{g}}(1)$ & $19 F(1)$ & & $271(1)$ & $19 F(1)$ & $271(2)$ & $19 F(2)$ & $N F^{b}(1)$ & $19 \mathrm{~A}(1)$ \\
\hline & $\overline{N F^{b, c}(2)}$ & $19 F(2)$ & & NT (1) & $19 \mathrm{~F}(1)$ & $1459^{\mathrm{b}}(2)$ & $19 \mathrm{~F}(1)$ & $N T^{e}(1)$ & NT \\
\hline & $\overline{N T^{d}(1)}$ & $19 \mathrm{~F}(1)$ & & & & $3039^{\mathrm{b}}(1)$ & $19 \mathrm{~F}(1)$ & & \\
\hline & & & & & & $1396^{\mathrm{b}, \mathrm{e}}(1)$ & $19 F(1)$ & & \\
\hline & & & & & & $N F^{\mathrm{b}}$ (3) & $19 F(2)$ & & \\
\hline & & & & & & NT (1) & & & \\
\hline Total for time period & $9(39.1 \%)$ & & & $6(40.0 \%)$ & & $31(58.5 \%)$ & & $27(67.5 \%)$ & \\
\hline \multirow[t]{11}{*}{ mef(E)-positive } & $236^{\mathrm{b}}(2)$ & 19F (2) & 0 & $376(2)$ & $6 \mathrm{~A}(2)$ & $2705(3)$ & $\begin{array}{l}33 \mathrm{~A} / \mathrm{F} / 37 \\
\text { (3) }\end{array}$ & $3280(3)$ & NT \\
\hline & $13^{9}(1)$ & NT & & $1186(2)$ & NT & $1186(3)$ & NT & $1379(2)$ & $6 C(2)$ \\
\hline & $156(1)$ & $6 \mathrm{~A}(1)$ & & $1556(1)$ & NT & $236^{\mathrm{b}}(2)$ & $19 F(2)$ & $162^{f}(1)$ & NT \\
\hline & $376(1)$ & 6A (1) & & $6422(1)$ & NT & $156(1)$ & $9 \mathrm{~V}(1)$ & $199(1)$ & 19A (1) \\
\hline & $384^{f}(1)$ & $6 \mathrm{~B}(1)$ & & $N T^{f}(1)$ & $6 C$ & $199(1)$ & $19 \mathrm{~A}(1)$ & $344(1)$ & NT \\
\hline & $384^{9}(1)$ & $6 \mathrm{~B}(1)$ & & & & $558(1)$ & 35B (1) & 1518 (1) & $6 \mathrm{~B}(1)$ \\
\hline & $\overline{N F^{g}(1)}$ & NT & & & & $1379(1)$ & $6 C(1)$ & NF (1) & 6A (1) \\
\hline & $\overline{N T}(2)$ & NT & & & & $3065(1)$ & $6 C(1)$ & & \\
\hline & $\overline{N T^{f}(1)}$ & NT & & & & $N F^{f}(1)$ & $19 F(1)$ & & \\
\hline & & & & & & NT (1) & $6 C(1)$ & & \\
\hline & & & & & & $N T^{f}(1)$ & NT & & \\
\hline Total for time period & $11(47.8 \%)$ & & & $7(46.7 \%)$ & & $16(30.2 \%)$ & & $10(25.0 \%)$ & \\
\hline \multirow[t]{2}{*}{ erm(B)-positive } & $315(2)$ & $6 \mathrm{~B}(2)$ & 0 & $63(1)$ & $\begin{array}{l}15 \mathrm{~A} / 15 \mathrm{~F} \\
\text { (1) }\end{array}$ & $63(5)$ & $\begin{array}{l}15 \mathrm{~A} / 15 \mathrm{~F} \\
(5)\end{array}$ & $63(2)$ & $\begin{array}{l}15 \mathrm{~A} / 15 \mathrm{~F} \\
(2)\end{array}$ \\
\hline & $3066^{9}(1)$ & $\begin{array}{l}18 \mathrm{~A} / \mathrm{B} / \mathrm{C} / \mathrm{F} \\
\text { (1) }\end{array}$ & & NT (1) & & $180(1)$ & $3(1)$ & & \\
\hline Total for time period & $3(13.1 \%)$ & & & $2(13.3 \%)$ & & $6(11.3 \%)$ & & $2(5.0 \%)$ & \\
\hline mef(A)-positive & & & & & & & & $1111(1)$ & $6 C(1)$ \\
\hline Total for time & 0 & & 0 & 0 & & 0 & & $1(2.5 \%)$ & \\
\hline $\begin{array}{l}\text { Total macrolide } \\
\text { resistant/Total no. } \\
\text { isolates collected }\end{array}$ & $\begin{array}{l}23 / 131 \\
(17.6 \%)\end{array}$ & $0 / 34(0 \%)$ & $\begin{array}{l}15 / 54 \\
(27.8 \%)\end{array}$ & $\begin{array}{l}53 / 223 \\
(23.8 \%)\end{array}$ & $\begin{array}{l}40 / 150 \\
(26.7 \%)\end{array}$ & & & & \\
\hline
\end{tabular}

a Serotype deduced by PCR; serotypes in bold are non-vaccine types

${ }^{b}$ Sequence type is a single locus variant of ST271

c NF, Sequence type not found in MLST database

${ }^{d}$ NT, Not typed

${ }^{\text {e }}$ Dual-positive with M-phenotype $(n=5)$

${ }^{\mathrm{f}}$ mef(E)-positive with $\mathrm{MLS}_{\mathrm{B}}$ phenotype $(\mathrm{n}=6)$

${ }^{\mathrm{g}}$ Invasive isolate $(\mathrm{n}=5)$

Sequence types and serotypes of the mef(E)-positive population remained diverse over the time period (Table 2, Figure 1). Out of 20 total sequence types identified in this population, only six were found in more than one two-year period, three of those in both pre- and post- vaccine introduction time periods. These include ST236, serotype 19F, the genotype of the highly dispersed Taiwan ${ }^{19 F}-14$ clone and likely ancestor to the CC271 lineages, ST376 of NVT 6A, and ST156, the genotype of the Spain ${ }^{9 \mathrm{~V}}-3$ clone in which serotype switching from 

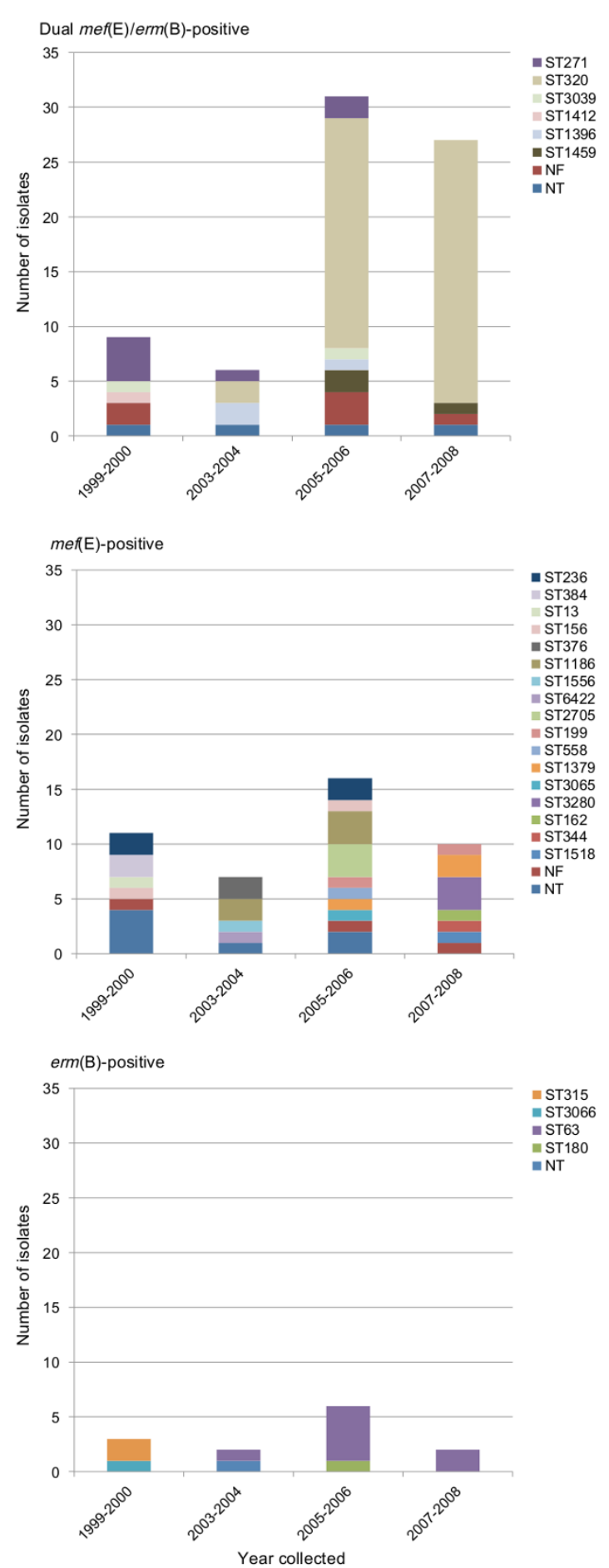

Figure 1 Changes in population structure over time in dual mef(E)/erm(B)-positive, mef(E)-positive, and erm(B)-positive $S$. pneumoniae clinical isolates. No isolates positive for mef(E) or erm (B) genes were collected in 2001-2002. ST, sequence type; NF, sequence type not found; NT, not typed
VT 9V to NVT 19A has been documented [35]. Interestingly, in the pre-vaccination time period, the ST156 strain is serotype 6A while the strain from the postvaccination time period likely is $9 \mathrm{~V}$. (PCR deduction typed the strain as $9 \mathrm{~V}$ or $9 \mathrm{~F}$.) The former was isolated from a 70 year-old male who may have received the 23-valent polysaccharide pneumococcal vaccine (PPSV) intended for adults over 65 years old and high-risk groups, and which covers serotype $9 \mathrm{~V}$. This strain may have switched from $9 \mathrm{~V}$ to $6 \mathrm{~A}$ in response to PPSV, before introduction of PCV7. Additionally, the mef(E)positive population illustrates serotype replacement. Historically VT strains caused most pneumococcal disease, however after 2000, more NVT strains than VT strains were found.

In the erm(B)-positive population, serotype replacement may also be evident. The early population is comprised of two ST315, VT 6B strains and a ST3066 strain, possibly VT 18C. (This isolate typed as 18A, B, $\mathrm{C}$, or F using PCR; the Pneumococcal Molecular Epidemiology Network [PMEN] clone database links ST3066 with serotype $18 \mathrm{C}$ [37].) They were replaced in later years by the unrelated ST63, NVT 15A or 15F (PMEN links ST63 with serotype 15A [37]) and ST180, NVT 3 (Table 2, Figure 1).

\section{mef(E) and erm(B) population characteristics: Specimen types}

Many $(\mathrm{n}=32)$ of the dual mef(E)/erm(B)-positive isolates were from ear specimens collected after 2000 (post-PCV7) from children of vaccine age (less than five years old after the introduction of the PCV7 in 2000). Many $(\mathrm{n}=32)$ were from respiratory specimens, only eight of which came from children of vaccine age; most came from adults post-PCV7. Similarly, a relatively large proportion of isolates of the $\operatorname{erm}(\mathrm{B})$-positive population was from ear $(n=4)$ or eye $(n=3)$ specimens from children of vaccine age, while most of the rest are from adult patients. In contrast, the mef(E)-positive population consists mostly of respiratory isolates $(n=25)$, and a large fraction of these $(n=21)$ are from older generations. A relatively small proportion was from ear specimens $(n=4)$ or eye specimens $(n=6)$ of children of vaccine age.

mef(E) and erm(B) population characteristics: MLST, antimicrobial resistance, transposon carriage

Analyses of genotypes of dual-positive isolates showed little diversity within the population; seven of the 73 dual mef(E)/erm(B)-positive isolates are ST271 and the remaining are SLVs of ST271 (Table 2). All 73 of the 
dual-positive isolates are multidrug-resistant. Most are resistant to penicillin, erythromycin, clindamycin, and trimethoprim-sulfamethoxazole and positive for tet(M); five were reported clindamycin-susceptible. Thirty-three dual-positive isolates representing all sequence types found were analyzed for transposon carriage. All 33 were positive for the genes int and xis, and with primer sets SG1/LTf and EB2/TN2, and negative for the genes $\operatorname{tnpR}$ and $\operatorname{tnp} A$, indicating carriage of Tn2010, the transposon known to harbor $\operatorname{erm}(\mathrm{B}), \operatorname{mef}(\mathrm{E})$, and tet(M) (Table 3). None apparently carried Tn2017. Although the dual positive population is the largest, it exhibits the lowest diversity of genotypes.

The $\operatorname{erm}(\mathrm{B})$-positive population is comprised of strains of four distinct sequence types, none of which match any from the dual-positive population (Table 2). Only one MLST allele is common to both populations. Despite MLST dissimilarity among the $\operatorname{erm}(\mathrm{B})$-positive isolates, all have similar antibiotic susceptibility profiles. Most are intermediately or fully susceptible to penicillin and trimethoprim-sulfamethoxazole while resistant to erythromycin and clindamycin, and all carry tet(M). Out of the 13 isolates in this population, all eight ST63 isolates were negative for int, xis, $\operatorname{tnpR}$, and $\operatorname{tnp} A$; the genetic context of their antibiotic resistance genes remains unknown. Two isolates, one ST3066 and a nontyped isolate, tested positive for $\operatorname{Tn} 916$ and $\operatorname{Tn} 917$, and produced an 800 bp PCR product with J12/J11 primers, signifying the presence of Tn3872. The two ST315 isolates and the ST180 isolate tested positive for Tn916, but were negative for Tn917 and with J12/J11, possibly indicating carriage of tet(M) in Tn916 and a separate erm(B) element (Table 3).

Genotype analyses of the mef(E)-positive population show high diversity with relatively even distribution. Besides three sets of SLVs, the highest number of MLST alleles shared by any two sequence types is three, and no more than four isolates of the same sequence type were identified. Many different antibiotic susceptibility profiles were identified in this population, with no single dominant profile. Of the $44 m e f(\mathrm{E})$-positive isolates, eight isolates of three sequence types, ST236, a SLV of ST236, and ST3280, were positive for int and xis, for the SG1/LTf region, and for tet(M), indicating the presence of Tn2009. Five others were positive for only int and $x i$ s and tet $(\mathrm{M})$, indicating carriage of Tn916 and a separate mega element. The absence of these transposon PCR targets and tet(M) in the other 31 isolates suggests they are carrying the mega element (Table 3 ).

\section{Discussion}

Macrolide resistance rates in clinical isolates of S. pneumoniae vary greatly among countries. The rate in our collection of isolates from Arizona patients, 23.6\%, is consistent with other studies targeting S. pneumoniae in North America [15,38].

The temporal trend in $m e f(\mathrm{E})$ and $\operatorname{erm}(\mathrm{B})$ prevalence that we observed in our collection, the rise in proportion dual gene-positive inversely to the proportion mef (E)-positive, is similar to those of other non-invasive isolate studies [39]. Recent studies of invasive isolates have shown low rates of dual gene carriage and multidrug resistance $[11,14,40]$. Likewise, only one of the invasive isolates we tested was dual-gene positive. These significant differences between invasive and non-invasive isolate gene carriage and susceptibility profiles may arise because macrolide-induced selection pressures on invasive $S$. pneumoniae may be different from those on noninvasive $S$. pneumoniae, due to the pharmacodynamics of macrolide antibiotics.

Over half of our macrolide resistant S. pneumoniae isolates are positive for both $\operatorname{erm}(\mathrm{B})$ and $m e f(\mathrm{E})$. All these dual-positive strains belong to CC271, have almost identical multidrug resistance profiles, and are likely carrying Tn2010. Clonal lineages of multidrug-resistant $S$. pneumoniae belonging to CC271 are now distributed worldwide and make up a significant portion of the macrolide resistant $S$. pneumoniae isolates in many regions $[7,10,14,41,42]$. The emergence of these clones is at least partly a response to introduction of PCV7, in which lineages of the successful multidrug resistant Taiwan $^{19 F}$-14 ST236 clone acquired $\operatorname{erm}(\mathrm{B})$ and switched serotypes in response to the selective pressures of an immunized population $[6,43]$. One cosmopolitan lineage recombined into ST320 and serotype 19A [35,36]. This clone has afflicted Arizona children since the PCV7 release in 2000; of the 73 dual-positive isolates in our collection, 47 are ST320, 38 of which are from children of vaccine age. Most of these are from ear and respiratory specimens, an observation consistent with that of the global PROTEKT studies $[6,15]$. These data display the opportunistic dominance of a few S. pneumoniae clones in the post-PCV7 era. The pervasiveness of the multidrug resistant phenotype poses a serious public health concern for increased treatment failure and selection of these clones with the usage of any one of several antibiotics.

Genotyping our collection revealed high strain diversity within the $m e f(\mathrm{E})$-positive population. The variety of antibiotic susceptibility profiles and mobile genetic elements carrying mef(E) reflect the sequence type and serotype diversity found in this population. These data indicate that mef(E)-carrying $S$. pneumoniae are the ancestral macrolide-resistant strains in the U.S. Serotype replacement and a possible serotype switching event are evident in this population; NVTs outnumber VTs in later time periods, and ST156, the identifier of the Spain $^{9 \mathrm{~V}}-3$ clone, typed as NVT 6A. One notable 
Table 3 Mobile genetic elements carrying erm(B) and mef(E) genes and associated genotypic and phenotypic profiles

\begin{tabular}{|c|c|c|c|c|}
\hline $\begin{array}{l}\text { Population Dual } \\
\text { mef(E)/erm(B)- }\end{array}$ & $\begin{array}{l}\text { Sequence } \\
\text { type } 320\end{array}$ & $\begin{array}{l}\text { Antibiotic susceptiblity profile } \\
\text { Pen }^{\text {ns }} \text { Ery }^{r} \mathrm{Cli}^{\mathrm{T}} \mathrm{Tet}^{\mathrm{r} / \mathrm{u}+} \mathrm{Sxt}^{\mathrm{r}}\end{array}$ & $\begin{array}{l}\text { Presumed transposon (no. isolates with same } \\
\text { profile tested) Tn2010 (12) }\end{array}$ & $\begin{array}{l}\text { Total no. isolates of } \\
\text { same profile } 43\end{array}$ \\
\hline & 320 & Pen ${ }^{\text {ns }}$ rry $^{r} \mathrm{Cli}^{\text {s }}$ Tet $^{r / \mathrm{u}} \mathrm{S} x \mathrm{t}^{r}$ & $\operatorname{Tn} 2010(1)$ & 2 \\
\hline & 320 & Pen $^{n s}$ Ery $^{r}$ Cli $^{r}$ Tet $^{\mathrm{u}-} \mathrm{S} x \mathrm{t}^{\mathrm{r}}$ & $\operatorname{Tn} 2010$ (1) & 2 \\
\hline & 271 & Pen $^{\text {ns }}$ Ery $^{r}$ ClirTet $^{r / u+}$ Sxt $^{r}$ & Tn2010 (5) & 7 \\
\hline & 1396 & Pen $^{r}$ Ery $^{r} \mathrm{Cli}^{\mathrm{r}} \mathrm{Tet}^{\mathrm{ns} / \mathrm{u}+} \mathrm{Sxt}^{\mathrm{r}}$ & $\operatorname{Tn} 2010(2)$ & 2 \\
\hline & 1396 & Pen $^{r}$ rry $^{r}$ Cli $^{s} T t^{n s / u+} S x t^{r}$ & $\operatorname{Tn} 2010(1)$ & 1 \\
\hline & 1459 & Pen Ery Cli Tet Sxt & Tn2010 (3) & 3 \\
\hline & 3039 & $\mathrm{Pen}^{\mathrm{r} / \mathrm{u}}$ Ery $^{r} \mathrm{Cli}^{r} \mathrm{Tet}^{r / \mathrm{u}+} \mathrm{S} x \mathrm{t}^{r}$ & $\operatorname{Tn} 2010(2)$ & 2 \\
\hline & $\overline{1412}$ & Pen $^{r}$ Ery $^{r} \mathrm{Cli}^{\mathrm{s}} \mathrm{Tet}^{\mathrm{r}} \mathrm{S} x \mathrm{t}^{\mathrm{r}}$ & $\operatorname{Tn} 2010(1)$ & 1 \\
\hline & $\overline{\mathrm{NF}}$ & Pen $^{\text {ns }}$ Ery $^{r} \mathrm{Cli}^{r} \mathrm{Tet}^{\mathrm{r} / \mathrm{u}+} \mathrm{Sxt}^{r}$ & $\operatorname{Tn} 2010$ (5) & 6 \\
\hline & $\overline{\mathrm{NT}}$ & Pen ${ }^{\text {ns }}$ Ery $^{r}$ Cli' $^{r}$ Tet $^{r / u+}$ Sxt $^{r}$ & NT & 3 \\
\hline \multirow[t]{16}{*}{ mef(E)-positive } & NT & Pen $^{\text {ns }}$ Ery $^{r} \mathrm{Cli}^{\mathrm{s}}$ Tet $^{\mathrm{r} S x t^{r}}$ & NT & 1 \\
\hline & 236 & Pen ${ }^{\text {ns }}$ rry $^{r} \mathrm{Cli}^{\text {ST Tet }}{ }^{r / \mathrm{u}} \mathrm{S} x \mathrm{t}^{r}$ & Tn2009 (4) & 4 \\
\hline & 1186 & 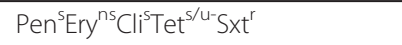 & mega (4) & 4 \\
\hline & 1186 & Pen $^{\text {ns }}$ Ery $^{r} \mathrm{Cli}^{\mathrm{s}}$ Tet $^{\mathrm{u}}{ }^{-} \mathrm{S} x \mathrm{t}^{\mathrm{r}}$ & mega (1) & 1 \\
\hline & 1379 & Pen $^{\text {ns }}$ Ery $^{r} \mathrm{Cli}^{\mathrm{s}} \mathrm{Tet}^{\mathrm{S}} \mathrm{S} x \mathrm{t}^{\mathrm{r}}$ & mega (2) & 2 \\
\hline & 1379 & Pen $^{5}$ Ery $^{r} \mathrm{Cli}^{\mathrm{s}} \mathrm{Tet}^{\mathrm{s}} \mathrm{S} x \mathrm{t}^{r}$ & mega (1) & 1 \\
\hline & 2705 & Pen $^{s}$ Ery $^{r} \mathrm{Cli}^{\mathrm{s}} \mathrm{Tet}^{\mathrm{s} / \mathrm{u}} \mathrm{s}$ Sxt $\mathrm{r}^{\mathrm{r}}$ & mega (3) & 3 \\
\hline & 3280 & Pen ${ }^{\text {ns }}$ rry $^{r} \mathrm{Cli}^{\mathrm{s}} \mathrm{Tet}^{\mathrm{r} / \mathrm{u}} \mathrm{S} x \mathrm{t}^{r}$ & $\operatorname{Tn} 2009$ (3) & 3 \\
\hline & 376 & Pen $^{\text {ns }}$ rry $^{r} \mathrm{Cli}^{\text {sTet }}{ }^{\text {s/u-Sxt }}{ }^{r}$ & mega (3) & 3 \\
\hline & 156 & Pen $^{\text {ns }}$ rry $^{r} \mathrm{Cli}^{\mathrm{s}} \mathrm{Tet}^{\mathrm{s} / \mathrm{u}}-\mathrm{S} x \mathrm{t}^{r}$ & mega (2) & 2 \\
\hline & 199 & Pen $^{\mathrm{s}}$ Ery $^{r} \mathrm{Cli}^{\mathrm{s}} \mathrm{Tet}^{\mathrm{s}} \mathrm{S} x \mathrm{t}^{\mathrm{s}}$ & mega (1) & 1 \\
\hline & 199 & Pen ${ }^{\text {ns }}$ Ery $^{r} \mathrm{Cli}^{\mathrm{s}} \mathrm{Tet}^{\mathrm{u}}{ }^{-} \mathrm{S} x \mathrm{t}^{\mathrm{r}}$ & mega (1) & 1 \\
\hline & 384 & Pen $^{r}$ Ery $^{r} \mathrm{Cli}^{r}$ Tet $^{s+}$ Sxt ${ }^{r}$ & Tn916+mega (1) & 1 \\
\hline & 384 & Pen $^{r}$ Ery $^{r} \mathrm{Cli}^{\mathrm{s}} \mathrm{Tet}^{\mathrm{r}} \mathrm{S} x \mathrm{t}^{\mathrm{s}}$ & Tn916+mega (1) & 1 \\
\hline & 13 & Pen $^{r}$ Ery $^{r} \mathrm{Cli}^{\mathrm{s}} \mathrm{Tet}^{\mathrm{s}} \mathrm{S} x \mathrm{t}^{\mathrm{r}}$ & mega (1) & 1 \\
\hline & 162 & Pen $^{\text {ns }}$ Ery $^{r}$ Cli $^{r}$ Tet $^{\mathrm{u}-S} \mathrm{Sxt}^{\mathrm{s}}$ & mega (1) & 1 \\
\hline \multirow[t]{19}{*}{ erm(B)-positive } & 344 & Pen $^{\text {ns }}$ Ery $^{r} \mathrm{Cli}^{s}$ Tet $^{\mathrm{u}+}$ Sxt ${ }^{r}$ & Tn916+mega (1) & 1 \\
\hline & 558 & Pen $^{\text {ns }}$ Ery $^{r} \mathrm{Cli}^{\text {s }}$ Tet $^{\mathrm{s}} \mathrm{S} x \mathrm{t}^{\mathrm{s}}$ & mega (1) & 1 \\
\hline & 1518 & Pen $^{\text {ns }}$ Ery $^{r} \mathrm{Cli}^{\mathrm{s}} \mathrm{Tet}^{\mathrm{s}} \mathrm{S} x \mathrm{t}^{\mathrm{r}}$ & mega (1) & 1 \\
\hline & 1556 & Pen $^{r}$ Ery $^{r} \mathrm{Cli}^{\mathrm{s}} \mathrm{Tet}^{\mathrm{u}}{ }^{-} \mathrm{S} x \mathrm{t}^{\mathrm{r}}$ & mega (1) & 1 \\
\hline & 3065 & Pen $^{\mathrm{s}}$ Ery $^{\mathrm{r}} \mathrm{Cli}^{\mathrm{S}}$ Tet $^{\mathrm{u}-\mathrm{S} x \mathrm{t}^{\mathrm{ns}}}$ & mega (1) & 1 \\
\hline & 6422 & Pen $^{r}$ Ery $^{r} \mathrm{Cli}^{\mathrm{s}} \mathrm{Tet}^{\mathrm{r}} \mathrm{S} x \mathrm{t}^{\mathrm{r}}$ & mega (1) & 1 \\
\hline & NF & Pen $^{r}$ Ery $^{r} \mathrm{Cli}^{\mathrm{s}} \mathrm{Tet}^{\mathrm{S}} \mathrm{S} x \mathrm{t}^{\mathrm{ns}}$ & mega (1) & 1 \\
\hline & NF & Pen $^{\text {ns }}$ Ery $^{r} \mathrm{Cli}^{\mathrm{s}} \mathrm{Tet}^{\mathrm{S}} \mathrm{S} x \mathrm{t}^{\mathrm{s}}$ & mega (1) & 1 \\
\hline & NF & Pen ${ }^{\text {ns }}$ rry $^{r} \mathrm{Cli}^{\text {ns }}$ Tet $^{\mathrm{u}+}{ }^{2} \mathrm{xt}^{\mathrm{r}}$ & $\operatorname{Tn} 2009$ (1) & 1 \\
\hline & NT & Pen $^{\text {ns }}$ Ery $^{r} \mathrm{Cli}^{r}{ }^{\prime}$ tet $^{u+} S x t^{s}$ & Tn916+mega (1) & 1 \\
\hline & NT & 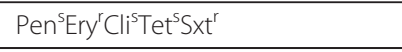 & mega (1) & 1 \\
\hline & NT & Pen $^{\mathrm{s}} \mathrm{Ery}^{\mathrm{r}} \mathrm{Cli}^{\mathrm{s}} \mathrm{Tet}^{\mathrm{s}} \mathrm{S} x \mathrm{t}^{\mathrm{s}}$ & mega (2) & 2 \\
\hline & NT & Pen $^{r}$ Ery ${ }^{r} C_{1 i}{ }^{r}$ Tet $^{r} S x t^{r}$ & Tn916+mega (1) & 1 \\
\hline & NT & Pen $^{r}$ Ery $^{r}$ Cli $^{r} T^{T} t^{\mathrm{u}}{ }^{-} S x t^{r}$ & mega (1) & 1 \\
\hline & 63 & 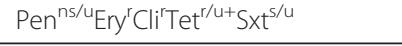 & erm(B) element (8) & 8 \\
\hline & 315 & Pen'Ery ${ }^{r} \mathrm{Cli}^{r} \mathrm{Tet}^{\mathrm{r}} \mathrm{S} x \mathrm{t}^{\mathrm{i}}$ & Tn916 family (2) & 2 \\
\hline & 3066 & Pen $^{\mathrm{s}}$ Ery $^{r} \mathrm{Cli}^{\mathrm{r}} \mathrm{Tet}^{\mathrm{r}} \mathrm{S} x \mathrm{t}^{\mathrm{s}}$ & $\operatorname{Tn} 3872(1)$ & 1 \\
\hline & 180 & Pen $^{\mathrm{s}}$ Ery $^{\mathrm{r}} \mathrm{Cli}^{r}{ }^{\mathrm{T}} \mathrm{Tt}^{\mathrm{r}} \mathrm{S} x \mathrm{t}^{\mathrm{s}}$ & Tn916 family (1) & 1 \\
\hline & NT & Pen $^{\text {E Ery }}{ }^{r} \mathrm{Cli}^{r}$ Tet $^{r} \mathrm{~S} x \mathrm{t}^{\mathrm{s}}$ & $\operatorname{Tn} 3872(1)$ & 1 \\
\hline
\end{tabular}

\footnotetext{
a Pen, penicillin; Ery, erythromycin; Cli, clindamycin; Tet, tetracycline; Sxt, trimethoprim-sulfamethoxazole; r, resistant; ns, nonsusceptible; s, susceptible; u, unknown phenotype; +, positive for tet(M) by $\mathrm{PCR}$; -, negative for tet(M) by PCR; NF, not found; NT, not typed
} 
observation of the mef(E)-positive population is that the latest ST236 seen is 2005-2006, more evidence that this clone acquired the $\operatorname{erm}(\mathrm{B})$ gene, and its lineages now comprise the dual mef(E)/erm(B)-positive population.

Genotype analyses of the small erm(B)-positive population illustrate serotype replacement. ST315, VT 6B is not seen after 2000, while ST63, NVT 15A became dominant [37]. These findings could be the result of loss in ST315 or acquisition in ST63 of erm(B) and consequent sampling bias, however neither strain carries $\operatorname{erm}(\mathrm{B})$ in a Tn917-family transposon leaving the mobility of the erm(B) element in these strains unknown.

The dramatic increase in erm(B)-carrying S. pneumoniae isolates is important in regions where mef-carrying isolates have historically predominated. Treatment with macrolides is an option for patients suffering localized infections caused by mef-carrying S. pneumoniae, as drug concentrations in tissues can supercede these bacteria's macrolide MICs [44,45]. However, macrolide MICs for erm(B)-carrying strains are significantly higher than those of mef-carrying isolates [46], increasing the need for alternative antibiotics where $\operatorname{erm}(\mathrm{B})$ predominates. It remains to be seen whether the U.S. will see an increase in clinical failure in macrolide-treated cases parallel to the increase in erm(B)-carrying $S$. pneumoniae.

\section{Conclusions}

Our Arizona-based study supports other global studies that illustrate the impact that PCV7 has had on the population structure of macrolide resistant S. pneumoniae in non-invasive isolates, and calls attention to the longevity of the success of particular multidrug resistant clones. The vaccine has reduced morbidity and mortality and multidrug resistance in invasive disease, but serotype replacement and serotype switching by $S$. pneumoniae has eclipsed these effects in non-invasive disease, and may soon for invasive disease $[8,35,47,48]$. However, the recently released PCV13, which covers serotypes of the newly dominant multidrug-resistant clones, including 19A, may have very different consequences for S. pneumoniae population genetics. Vaccine response and population genetics studies are important to our understanding of $S$. pneumoniae evolution and strain dominance. More accessible higher resolution technology, for example whole genome sequencing, provides us with more information than MLST, resistance gene profiling, targeted transposon investigation, and serotyping combined [49]. Consequently, future studies that include next generation sequencing would help to better and more quickly elucidate the effects of $S$. pneumoniae infection prevention and treatment strategies.

\section{Acknowledgements}

Special thanks are in order for TGen's administrative staff, Tricia O'Reilly and Michael Bork, for their continual support of our scientific endeavors. The project described was supported by award number U01Al066581 and 1R01Al090782-01 from the National Institute of Allergy and Infectious Diseases. The content is solely the responsibility of the authors and does not necessarily represent the official views of the National Institute of Allergy and Infectious Diseases or the National Institutes of Health.

\section{Author details}

${ }^{1}$ Translational Genomics Research Institute, Flagstaff, AZ, USA. ${ }^{2}$ Laboratory Sciences of Arizona, Tempe, AZ, USA. ${ }^{3}$ Northern Arizona University, Flagstaff, AZ, USA. ${ }^{4}$ Life Technologies, Foster City, CA, USA. ${ }^{5}$ University of Arizona, Tucson, AZ, USA.

\section{Authors' contributions}

JRB participated in the molecular data collection, analysis, and interpretation, and drafted the manuscript. EMD designed the study and was involved in critically revising the manuscript. JLN participated in the molecular data collection and analysis. BRW conducted the microbiological methods and analyzed and interpreted data. DSS participated in data collection and was involved in critically revising the manuscript. AHW and PMB designed the assays and methods for real-time PCR. NH and AK participated in molecular data collection, analysis and interpretation. LMW participated in data collection and analysis. DMW participated in data collection and was involved in critically revising the manuscript. MRF, MS, DME, and PSK conceived of and designed the study. All authors read and approved the final manuscript.

Received: 2 October 2011 Accepted: 18 January 2012 Published: 18 January 2012

\section{References}

1. Skalet AH, Cevallos V, Ayele B, Gebre T, Zhou Z, Jorgensen JH, Zerihun M, Habte D, Assefa Y, Emerson PM, et al: Antibiotic selection pressure and macrolide resistance in nasopharyngeal streptococcus pneumoniae: a cluster-randomized clinical trial. PLoS Med 2010, 7(12):e1000377.

2. Karlowsky JA, Lagace-Wiens PR, Low DE, Zhanel GG: Annual macrolide prescription rates and the emergence of macrolide resistance among Streptococcus pneumoniae in Canada from 1995 to 2005. Int J Antimicrob Agents 2009, 34(4):375-379.

3. Klugman KP: Clinical impact of antibiotic resistance in respiratory tract infections. Int J Antimicrob Agents 2007, 29(Suppl 1):S6-10.

4. Lonks JR, Garau J, Gomez L, Xercavins M, de Ochoa Echaguen A, Gareen IF, Reiss PT, Medeiros AA: Failure of macrolide antibiotic treatment in patients with bacteremia due to erythromycin-resistant Streptococcus pneumoniae. Clin Infect Dis 2002, 35(5):556-564.

5. Dagan $\mathrm{R}$, Leibovitz $\mathrm{E}$ : Bacterial eradication in the treatment of otitis media. Lancet Infect Dis 2002, 2(10):593-604

6. Farrell DJ, Couturier C, Hryniewicz W: Distribution and antibacterial susceptibility of macrolide resistance genotypes in Streptococcus pneumoniae: PROTEKT year 5 (2003-2004). Int J Antimicrob Agents 2008, 31(3):245-249.

7. Xu X, Cai L, Xiao M, Kong F, Oftadeh S, Zhou F, Gilbert GL: Distribution of serotypes, genotypes, and resistance determinants among macrolideresistant Streptococcus pneumoniae isolates. Antimicrob Agents Chemother 2010, 54(3):1152-1159.

8. Mera RM, Miller LA, Amrine-Madsen H, Sahm DF: The impact of the pneumococcal conjugate vaccine on antimicrobial resistance in the United States since 1996: evidence for a significant rebound by 2007 in many classes of antibiotics. Microb Drug Resist 2009, 15(4):261-268.

9. Song JH, Chang HH, Suh JY, Ko KS, Jung SI, Oh WS, Peck KR, Lee NY, Yang $Y$, Chongthaleong $A$, et al: Macrolide resistance and genotypic characterization of Streptococcus pneumoniae in Asian countries: a study of the Asian Network for Surveillance of Resistant Pathogens (ANSORP). J Antimicrob Chemother 2004, 53(3):457-463.

10. Reinert RR, Filimonova OY, Al-Lahham A, Grudinina SA, Ilina EN, Weigel LM, Sidorenko SV: Mechanisms of macrolide resistance among Streptococcus pneumoniae isolates from Russia. Antimicrob Agents Chemother 2008, 52(6):2260-2262 
11. de la Pedrosa EG, Baquero F, Loza E, Nadal-Serrano JM, Fenoll A, Del Campo R, Canton R: High clonal diversity in erythromycin-resistant Streptococcus pneumoniae invasive isolates in Madrid, Spain (2000-07). J Antimicrob Chemother 2009, 64(6):1165-1169.

12. McGee L, Klugman KP, Wasas A, Capper T, Brink A: Serotype $19 f$ multiresistant pneumococcal clone harboring two erythromycin resistance determinants (erm(B) and mef(A)) in South Africa. Antimicrob Agents Chemother 2001, 45(5):1595-1598.

13. Daoud Z, Kourani M, Saab R, Nader MA, Hajjar M: Resistance of Streptococcus pneumoniae isolated from Lebanese patients between 2005 and 2009. Rev Esp Quimioter 2011, 24(2):84-90.

14. Siira L, Rantala M, Jalava J, Hakanen AJ, Huovinen P, Kaijalainen T, Lyytikainen $O$, Virolainen A: Temporal trends of antimicrobial resistance and clonality of invasive Streptococcus pneumoniae isolates in Finland, 2002-2006. Antimicrob Agents Chemother 2009, 53(5):2066-2073.

15. Farrell DJ, Jenkins SG, Brown SD, Patel M, Lavin BS, Klugman KP. Emergence and spread of Streptococcus pneumoniae with erm(B) and mef(A) resistance. Emerg Infect Dis 2005, 11(6):851-858.

16. Zhanel GG, Wang X, Nichol K, Nikulin A, Wierzbowski AK, Mulvey M, Hoban DJ: Molecular characterisation of Canadian paediatric multidrugresistant Streptococcus pneumoniae from 1998 to 2004. Int J Antimicrob Agents 2006, 28(5):465-471.

17. Farrell DJ, Morrissey I, Bakker S, Morris L, Buckridge S, Felmingham D: Molecular epidemiology of multiresistant Streptococcus pneumoniae with both erm(B)- and mef(A)-mediated macrolide resistance. J Clin Microbiol 2004, 42(2):764-768.

18. Toltzis P, Dul M, O'Riordan MA, Jacobs MR, Blumer J: Serogroup 19 pneumococci containing both mef and erm macrolide resistance determinants in an American city. Pediatr Infect Dis J 2006, 25(1):19-24.

19. Bley $C$, van der Linden $M$, Reinert RR: $\operatorname{mef}(A)$ is the predominant macrolide resistance determinant in Streptococcus pneumoniae and Streptococcus pyogenes in Germany. Int J Antimicrob Agents 2011, 37(5):425-431.

20. Varaldo PE, Montanari MP, Giovanetti E: Genetic elements responsible for erythromycin resistance in streptococci. Antimicrob Agents Chemother 2009, 53(2):343-353.

21. Del Grosso M, Camilli R, Libisch B, Fuzi M, Pantosti A: New composite genetic element of the Tn916 family with dual macrolide resistance genes in a Streptococcus pneumoniae isolate belonging to clonal complex 271. Antimicrob Agents Chemother 2009, 53(3):1293-1294.

22. CLSI: Performance Standards for Antimicrobial Susceptibility Testing: 18th Informational Supplemen. CLSI document M100-S18 Wayne, PA: Clinical and Laboratory Standards Institute; 2008.

23. Enright MC, Spratt BG: A multilocus sequence typing scheme for Streptococcus pneumoniae: identification of clones associated with serious invasive disease. Microbiology 1998, 144(Pt 11):3049-3060.

24. da Gloria Carvalho M, Pimenta FC, Jackson D, Roundtree A, Ahmad Y, Millar EV, O'Brien KL, Whitney CG, Cohen AL, Beall BW: Revisiting pneumococcal carriage by use of broth enrichment and PCR techniques for enhanced detection of carriage and serotypes. Journal of clinical microbiology 2010, 48(5):1611-1618.

25. Dias CA, Teixeira LM, Carvalho Mda G, Beall B: Sequential multiplex PCR for determining capsular serotypes of pneumococci recovered from Brazilian children. J Med Microbiol 2007, 56(Pt 9):1185-1188.

26. Pai R, Gertz RE, Beall B: Sequential multiplex PCR approach for determining capsular serotypes of Streptococcus pneumoniae isolates. $J$ Clin Microbiol 2006, 44(1):124-131.

27. Pimenta FC, Gertz RE Jr, Roundtree A, Yu J, Nahm MH, McDonald RR, Carvalho Mda G, Beall BW: Rarely occurring 19A-like cps locus from a serotype $19 \mathrm{~F}$ pneumococcal isolate indicates continued need of serology-based quality control for PCR-based serotype determinations. J Clin Microbiol 2009, 47(7):2353-2354

28. Jin P, Xiao M, Kong F, Oftadeh S, Zhou F, Liu C, Gilbert GL: Simple, accurate, serotype-specific PCR assay to differentiate Streptococcus pneumoniae serotypes 6A, 6B, and 6C. J Clin Microbiol 2009, 47(8):2470-2474

29. Brenciani A, Bacciaglia A, Vecchi M, Vitali LA, Varaldo PE, Giovanetti E: Genetic elements carrying erm(B) in Streptococcus pyogenes and association with tet(M) tetracycline resistance gene. Antimicrob Agents Chemother 2007, 51(4):1209-1216.
30. Del Grosso M, Scotto d'Abusco A, lannelli F, Pozzi G, Pantosti A: Tn2009, a Tn916-like element containing mef(E) in Streptococcus pneumoniae. Antimicrob Agents Chemother 2004, 48(6):2037-2042.

31. Pantosti A, D'Ambrosio F, Bordi E, Scotto D'Abusco A, Del Grosso M: Activity of quinupristin-dalfopristin in invasive isolates of Streptococcus pneumoniae from Italy. Clin Microbiol Infect 2001, 7(9):503-506.

32. Del Grosso M, Camilli R, lannelli F, Pozzi G, Pantosti A: The mef(E)-carrying genetic element (mega) of Streptococcus pneumoniae: insertion sites and association with other genetic elements. Antimicrob Agents Chemother 2006, 50(10):3361-3366.

33. Cochetti I, Tili E, Mingoia M, Varaldo PE, Montanari MP: erm(B)-carrying elements in tetracycline-resistant pneumococci and correspondence between Tn1545 and Tn6003. Antimicrob Agents Chemother 2008, 52(4):1285-1290

34. Cochetti I, Tili E, Vecchi M, Manzin A, Mingoia M, Varaldo PE, Montanari MP: New Tn916-related elements causing erm(B)-mediated erythromycin resistance in tetracycline-susceptible pneumococci. J Antimicrob Chemother 2007, 60(1):127-131.

35. Moore MR, Gertz RE Jr, Woodbury RL, Barkocy-Gallagher GA, Schaffner W, Lexau C, Gershman K, Reingold A, Farley M, Harrison LH, et al: Population snapshot of emergent Streptococcus pneumoniae serotype 19A in the United States, 2005. J Infect Dis 2008, 197(7):1016-1027.

36. Pai R, Moore MR, Pilishvili T, Gertz RE, Whitney CG, Beall B: Postvaccine genetic structure of Streptococcus pneumoniae serotype 19A from children in the United States. J Infect Dis 2005, 192(11):1988-1995.

37. McGee L, McDougal L, Zhou J, Spratt BG, Tenover FC, George R, Hakenbeck R, Hryniewicz W, Lefevre JC, Tomasz A, et al: Nomenclature of major antimicrobial-resistant clones of Streptococcus pneumoniae defined by the pneumococcal molecular epidemiology network. J Clin Microbiol 2001, 39(7):2565-2571.

38. Jenkins SG, Brown SD, Farrell DJ: Trends in antibacterial resistance among Streptococcus pneumoniae isolated in the USA: update from PROTEKT US Years 1-4. Ann Clin Microbiol Antimicrob 2008, 7:1.

39. Farrell DJ, File TM, Jenkins SG: Prevalence and antibacterial susceptibility of mef(A)-positive macrolide-resistant Streptococcus pneumoniae over 4 years (2000-2004) of the PROTEKT US Study. J Clin Microbiol 2007, 45(2):290-293.

40. Calatayud L, Ardanuy C, Tubau F, Rolo D, Grau I, Pallares R, Martin R, Linares J: Serotype and genotype replacement among macrolideresistant invasive Pneumococci in adults: mechanisms of resistance and association with different transposons. J Clin Microbiol 2010, 48(4):1310-1316

41. Li Y, Tomita H, Lv Y, Liu J, Xue F, Zheng B, Ike Y: Molecular characterization of erm(B)- and mef(E)-mediated erythromycin-resistant Streptococcus pneumoniae in China and complete DNA sequence of Tn2010. J Appl Microbiol 2011, 110(1):254-265.

42. Siira L, Jalava J, Tissari P, Vaara M, Kaijalainen T, Virolainen A: Clonality behind the increase of multidrug-resistance among non-invasive pneumococci in Southern Finland. European journal of clinical microbiology \& infectious diseases: official publication of the European Society of Clinical Microbiology 2011.

43. Del Grosso M, Northwood JG, Farrell DJ, Pantosti A: The macrolide resistance genes erm(B) and mef(E) are carried by Tn2010 in dual-gene Streptococcus pneumoniae isolates belonging to clonal complex CC271. Antimicrob Agents Chemother 2007, 51(11):4184-4186.

44. Rzeszutek M, Wierzbowski A, Hoban DJ, Conly J, Bishai W, Zhanel GG: A review of clinical failures associated with macrolide-resistant Streptococcus pneumoniae. Int J Antimicrob Agents 2004, 24(2):95-104.

45. Noreddin AM, Roberts D, Nichol K, Wierzbowski A, Hoban DJ, Zhanel GG: Pharmacodynamic modeling of clarithromycin against macrolideresistant [PCR-positive mef(A) or erm(B)] Streptococcus pneumoniae simulating clinically achievable serum and epithelial lining fluid freedrug concentrations. Antimicrob Agents Chemother 2002, 46(12):4029-4034.

46. Wierzbowski AK, Nichol K, Laing N, Hisanaga T, Nikulin A, Karlowsky JA, Hoban DJ, Zhanel GG: Macrolide resistance mechanisms among Streptococcus pneumoniae isolated over 6 years of Canadian Respiratory Organism Susceptibility Study (CROSS) (1998 2004). J Antimicrob Chemother 2007, 60(4):733-740.

47. Reingold A, Hadler J, Farley MM, Harrison GL, Lynfield R, Besser J, Bennett N, Thomas A, Schaffner W, Beall B, Pilishvili T, Whitney CG, Moore M, Burton DC: Direct and indirect effects of routine vaccination of children 
with 7-valent pneumococcal conjugate vaccine on incidence of invasive pneumococcal disease-United States, 1998-2003. MMWR Morb Mortal Wkly Rep 2005, 54(36):893-897.

48. Mayers DL, Lerner SA, Ouellette M, Sobel JD: Antimicrobial drug resistanc Totowa, N.J.: Humana Press; 2009.

49. Croucher NJ, Harris SR, Fraser C, Quail MA, Burton J, van der Linden M, McGee L, von Gottberg A, Song JH, Ko KS, et al: Rapid pneumococcal evolution in response to clinical interventions. Science 2011, 331(6016):430-434

doi:10.1186/1471-2180-12-12

Cite this article as: Bowers et al.: Dominance of multidrug resistant CC271 clones in macrolide-resistant Streptococcus pneumoniae in Arizona. BMC Microbiology 2012 12:12

Submit your next manuscript to BioMed Central and take full advantage of:

- Convenient online submission

- Thorough peer review

- No space constraints or color figure charges

- Immediate publication on acceptance

- Inclusion in PubMed, CAS, Scopus and Google Scholar

- Research which is freely available for redistribution

Submit your manuscript at www.biomedcentral.com/submit 